\title{
LXR, a nuclear receptor that defines a distinct retinoid response pathway
}

\author{
Patricia J. Willy, ${ }^{1}$ Kazuhiko Umesono, ${ }^{2,4}$ Estelita S. Ong, ${ }^{2}$ Ronald M. Evans, ${ }^{2}$ \\ Richard A. Heyman, ${ }^{3}$ and David J. Mangelsdorf ${ }^{1,5}$ \\ ${ }^{1}$ Howard Hughes Medical Institute and Department of Pharmacology, University of Texas Southwestern Medical Center \\ at Dallas, Dallas, Texas 75235-9050 USA; ${ }^{2}$ Howard Hughes Medical Institute and The Salk Institute for Biological Studies, \\ San Diego, California 92186-5800 USA; ${ }^{3}$ Ligand Pharmaceuticals, Inc., San Diego, California 92121 USA
}

\begin{abstract}
We have identified a new retinoid response pathway through which 9-cis retinoic acid (9cRA) activates transcription in the presence of $L X R \alpha$, a member of the nuclear receptor superfamily. LXR $\alpha$ shows a specific pattern of expression in visceral organs, thereby restricting the response to certain tissues. Retinoid trans-activation occurs selectively on a distinct response element termed an LXRE. Significantly, neither RXR homodimers nor RXR/RAR heterodimers are able to substitute for LXR $\alpha$ in mediating this retinoid response. We provide evidence that the retinoid response on the LXRE is the result of a unique interaction between LXR $\alpha$ and endogenous RXR, which, unlike in the RXR/RAR heterodimer, makes RXR competent to respond to retinoids. Thus, the interaction with $L X R \alpha$ shifts RXR from its role described previously as a silent, DNA-binding partner to an active ligand-binding subunit in mediating retinoid responses through target genes defined by LXREs.
\end{abstract}

[Key Words: $\mathrm{RXR}_{\text {; }} \mathrm{LXR}$; orphan receptor; retinoid receptors; 9-cis retinoic acid; methoprene acid]

Received February 1, 1995; revised version accepted March 17, 1995.

All-trans retinoic acid (atRA) and 9-cis retinoic acid ( $9 \mathrm{cRA}$ ) are metabolites of vitamin A that mediate tissuespecific expression of target genes through their binding to two classes of nuclear hormone receptors, the retinoic acid receptors (RARs) and retinoid X receptors (RXRs) (for review, see Kastner et al. 1994b; Mangelsdorf et al. 1994). 9cRA is a high-affinity ligand for both RARs and RXRs, whereas atRA is a ligand for only RARs. Like other members of the nuclear receptor superfamily, the retinoid receptors trans-activate their target genes by binding to specific sites called hormone response elements found within their target gene's regulatory region. The highest affinity hormone response elements for the retinoid receptors, as well as the vitamin $D$ receptor (VDR), thyroid hormone receptors (TRs), and peroxisome proliferator activated receptors (PPARs), have been characterized as direct repeats (DRs) of the canonical hexad, AGGTCA, separated by 1-5 nucleotides (for review, see Giguère 1994; Mangelsdorf et al. 1994). RAR, VDR, TR, and PPAR preferentially bind to their hormone response elements in vitro as heterodimers complexed with RXR (Leid et al. 1992a; Glass 1994; Mangelsdorf et al. 1994). Reconstitution studies in yeast (Allegretto et al. 1993; Heery et al. 1993; Sande and Privalsky 1994) and RXR gene disruption experiments in mice (Kastner et al.

\footnotetext{
${ }^{4}$ Present address: Nara Institute of Science and Technology, 8916-5 Takayama, Ikoma, Nara 630-01, Japan.

${ }^{5}$ Corresponding author.
}

1994a; Sucov et al. 1994) have confirmed the function of the RXR heterodimer and suggest that it has an obligatory role in vivo as well as in vitro. Thus, RXRs appear to be essential pleiotropic regulators of several signaling pathways.

In terms of retinoid signaling, two distinct pathways are known, the RXR/RAR heterodimer and the RXR homodimer. The RXR/RAR heterodimer mediates atRA or 9cRA action through its high-affinity binding to DR5 (and to some extent DR2) elements. Recently, it has been shown that when the RXR/RAR heterodimer is bound to DNA, RXR occupies the 5' half-site and RAR occupies the 3' half-site of the DR5 element (Kurokawa et al. 1993; Perlmann et al. 1993). Direct ligand- and DNAbinding experiments have shown that in this configuration RXR is unable to bind ligand and thus functions as a silent partner (Kurokawa et al. 1994). The role of RXR as a silent partner is consistent with the finding that other receptors that heterodimerize with RXR do not require 9cRA for their activation (Yu et al. 1991; Kliewer et al. 1992a,b; Leid et al. 1992b; Marks et al. 1992; Zhang et al. 1992a). RXR can also act as its own partner to form a homodimer and mediate 9cRA action through binding to DR1 elements. Interestingly, the RXR/RAR heterodimer also binds the DRl element and with higher affinity than the RXR homodimer. In many cell types, the consequence of this binding is that the RXR/RAR heterodimer is a potent repressor of ligand activation through the RXR homodimer (Mangelsdorf et al. 1991; Kurokawa et 
al. 1994|. These findings suggest that for the RXR homodimer to be active (i.e., for RXR to be able to function as a 9cRA receptor in vivol, the ratio of RXR to RAR in a cell must be very high. This may explain why certain cells that endogenously express RXR and RAR (even at low levels) yield significant retinoid responses with DR5-containing reporter genes but do not yield any response with DR1-containing reporter genes unless RXRs are overexpressed in these cells (Mangelsdorf et al. 1991). Given the ubiquitous expression pattern of RARs and RXRs, one question is whether 9cRA activation of RXR through DRl elements is the only pathway that exists for mediating a 9cRA-RXR response.

In this paper we report the identification of an orphan member of the nuclear receptor superfamily, named LXR $\alpha$. In the presence of 9cRA, LXR $\alpha$ is required for trans-activation through a distinct retinoid response element. Our data indicate that the LXR $\alpha$ response to retinoid is attributable to its unique interaction with endogenous RXR in cells. This interaction permits RXR to work as an active, ligand-binding heterodimeric partner. These results demonstrate the ability of LXR $\alpha$ to function as a tissue-specific mediator of a novel 9cRA response pathway.

\section{Results}

\section{Molecular cloning of human $L X R \alpha$}

Sequential low-stringency screening of a human liver $\lambda$ gtl 1 cDNA library with a cDNA probe encoding the human RAR $\alpha$ DNA-binding domain led to the isolation of several potential nuclear receptor clones. Preliminary DNA sequencing analysis revealed that a subset of these clones encoded a single novel orphan nuclear receptor. Based on its initial isolation from the liver and its liverrich expression pattern (see below), this orphan receptor was referred to as $\mathrm{LXR} \alpha$. The longest $\mathrm{LXR} \alpha$ cDNA was subcloned (see Materials and methods) and completely sequenced (Fig. 1). Eighteen base pairs downstream from an in-frame termination codon at nucleotide 127 is the predicted translation start codon for $\mathrm{LXR} \alpha$ at nucleotide 148. Translation from this ATG predicts an LXR $\alpha$ protein of 447 amino acids $\left(M_{r} 49,000\right)$ that we have confirmed by in vitro transcription/translation /data not shown) of the LXR $\alpha$ cDNA depicted in Figure 1. This clone also contains 188 bp of $3^{\prime}$-untranslated region (UTR) that includes a canonical polyadenylation signal and a tract of 33 adenosines of the presumptive poly(A) tail. From these results we conclude that this cDNA encodes the full-length $\operatorname{LXR} \alpha$ protein.

A comparison of human LXR $\alpha$ with a number of other known receptors is depicted in Figure 2. Human (h)LXR $\alpha$ shares closest similarity with two recently reported orphan receptor sequences, rat RLD-1 (Apfel et al. 1994) and human NER or UR (Shinar et al. 1994; Song et al. 1994). Although the functional relationship of these proteins to $\mathrm{LXR} \alpha$ is not yet known, one of these receptors, RLD-1, is $92 \%$ identical, suggesting that it is the rat homolog of hLXR $\alpha$. These findings when combined with genomic Southern analysis and evaluation of other LXRrelated cDNAs (data not shown) indicate that LXR/ RLD-1 constitutes a gene family of at least two members. Interestingly, $h L X R \alpha$ also shares close identity with the Drosophila ecdysone receptor (dEcR), having a $71 \%$ similar DNA-binding domain and $39 \%$ similar putative ligand-binding domain. The degree of sequence identity of $\mathrm{hLXR} \alpha$ with the human receptors, however, is much less, but overall it is greatest with the human vitamin $\mathrm{D}$ receptor ( $\mathrm{hVDR}$ ). Of the nonsteroid subclass of receptors with known ligands, hLXR $\alpha$ has the lowest similarity to hRXR $\alpha$ (52\% in the DNA-binding domain; $22 \%$ in the ligand-binding domain).

\section{LXR expression pattern}

Northern blot analyses were performed to determine the tissue distribution and developmental pattern of LXR $\alpha$ gene expression. Poly $(A)^{+}$RNA isolated from a variety of adult rat tissues (Fig. 3a) or from staged whole mouse embryos (Fig. 3b) was size-fractionated, transferred to nylon filters, and hybridized with the hLXR $\alpha$ cDNA. The distribution of $L X R \alpha$ mRNA reveals an expression pattern similar to that of $\operatorname{RXR} \alpha$ (Mangelsdorf et al. 1990), with strong expression in metabolic organs such as liver, kidney, and intestine. The 1.9-kb $\mathrm{LXR} \alpha$ mRNA is also notably present in spleen and to a lesser extent in the adrenals. Analysis of expression during mouse development indicates that low levels of $\operatorname{LXR} \alpha$ are detected at embryonic day 13.5 and continue to increase in abundance through parturition.

\section{$L X R \alpha$ trans-activation by retinoids}

To identify a potential ligand for the orphan receptor $\mathrm{LXR} \alpha$, we employed a cell-based cotransfection screening assay similar to that used to successfully identify the RXR ligand (Mangelsdorf et al. 1990; Heyman et al. 1992). Initially, an LXR-responsive gene was unknown; therefore our preliminary experiments were designed to first identify an LXR-specific DNA-binding sequence that could serve as an LXR-responsive element (referred to as an LXRE). During the course of these experiments, we discovered a specific, high-affinity DNA-binding site for $\mathrm{LXR} \alpha$ in the promoter sequences of $\triangle \mathrm{MTV}$, a promoter derived from the mouse mammary tumor virus LTR (discussed below; see Fig. 6, below). This discovery suggested that the $\triangle$ MTV LXRE sequence could be transferred to a heterologous promoter, such as thymidine kinase (TK), and used with a luciferase (LUC) reporter gene for screening potential LXR $\alpha$ ligands. Thus, an assay system was established by transfecting CV-1 cells with an expression plasmid harboring the cDNA for LXR $\alpha$ and the LUC reporter plasmid TK-LXRE3-LUC (Fig. 4a). In a comprehensive screen of several classes of compounds, we found that $\operatorname{LXR} \alpha$ activation is only induced by the presence of certain retinoid ligands. Remarkably, LXR $\alpha$ is strongly activated by both 9cRA and methoprene acid (MA), which we have shown previously to be an RXR-specific ligand (Harmon et al. 1995). LXR $\alpha$ and retinoid are both required to confer trans-activation 
1 GATATCCGTGACATCATTGCCTGAGTCCACTGCAAAAAGCTGTCCCCAGAGCAGGAGGGCAATGACAGCTCCCAGGGCACTCATCTTGAC 91 TGCTCTTGCCTGGGGATTTGGACAGTGCCTTGGTAATGACCAGGGCTCCAGAAMGAG 10 $\begin{array}{cccc} & \text { M L W L G A P V P } \\ 20 & 30 & & \\ 181 \text { ATTCCTCCTGACTCTGCGGTGGAGCTGTGGAAGCAGGCGCACAGGATGCAAGCAGCCAGGCCCAGGGAGGCAGCAGCTGCATCCTC }\end{array}$ I P P D S A V E L W K P G A O D A S S O A Q G G S S C I I $50 \quad 60$

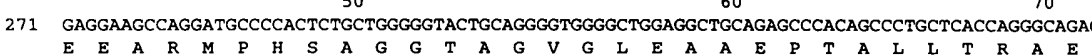

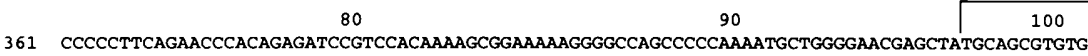

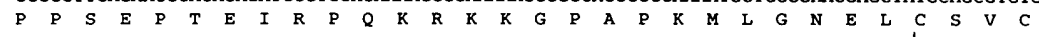

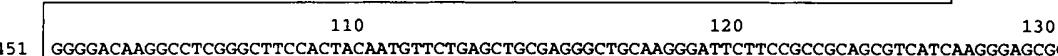
$\begin{array}{llllllllllllllllllllllllllllllll}\text { G } & D & \text { K } & \text { A } & \text { S } & \text { G } & \text { F } & \text { H } & \text { Y } & \text { N } & \text { V } & \text { L } & \text { S } & \text { C } & \text { E } & \text { G } & \text { C } & \text { K } & \text { G } & \text { F } & \text { F } & R & \text { R } & \text { S } & \text { V } & \text { I } & \text { K } & G & \text { A } & H\end{array}$ $\begin{array}{ccc}140 & 150 & 160\end{array}$

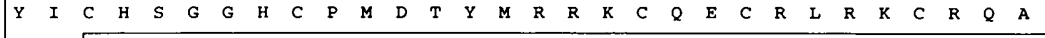
631 GGCATGCGGGGGATO 170

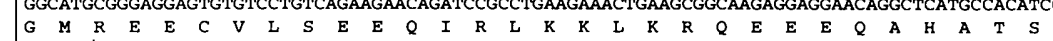
$21200 \quad 210 \quad 220$

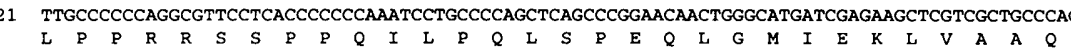
$230 \quad 240 \quad 250$

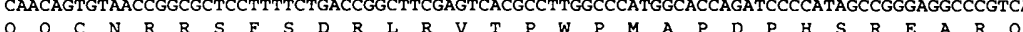
260 260

901 CAgCGCTTTGCCCACTTCACTGA $270 \quad 280$

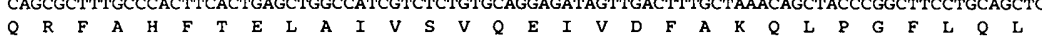
$290 \quad 300 \quad 310$ 991 AGCCGGGAGGACCAGATTGCCCTGCTGAAGACCTCTGCGATCGAGGTGATGCTTCTGGAGACATCTCGGAGTACAACCCTGGGAGTGA $\begin{array}{llllllllllllllllllllllllllllllll}S & R & E & D & Q & I & A & L & L & K & T & S & A & I & E & V & M & L & L & E & T & S & R & R & Y & N & P & G & S & E\end{array}$ $320 \quad 330 \quad 340$ 1081 AGTATCACCTTCCTCAAGGATTTCAGTTATAACCGGGAAGACTTTGCCAAAGCAGGGCTGCAAGTGGAATTCATCAACCCCATCTTCGAG

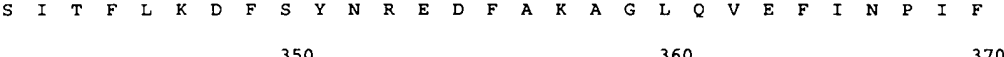
$350 \quad 360 \quad 370$ 1171 TTCTCCAGGGCCATGAATGAGCTGCAACTCAATGATGCCGAGTCCTTGCTCATTGCTATCAGCATCTTCTCTGCAGACCGGCCAA $\begin{array}{llllllllllllllllllllllllllllllll}\text { F } & S & R & A & M & \text { N } & \text { E } & \text { L } & \text { Q } & \text { L } & \text { N } & \text { D } & \text { A } & \text { E } & \text { F } & \text { A } & \text { L } & \text { L } & \text { I } & \text { A } & \text { I } & \text { S } & \text { I } & \text { F } & \text { S } & \text { A } & \text { D } & \text { R } & \text { P } & \text { N }\end{array}$ $380 \quad 390 \quad 400$ 1261 GTGCAGGACCAGCTCCAGGTGGAGAGGCTGCAGCACACATATGTGGAAGCCCTGCATGCCTACGTCTCCATCCACCATCCCCATGACCG $\begin{array}{lllllllllllllllllllllllllllllll}V & Q & D & Q & L & Q & V & E & R & L & Q & H & T & Y & V & E & A & L & H & A & Y & V & S & I & H & H & P & H & D & R\end{array}$ $410 \quad 420 \quad 430$ 1351 CTGATGTTCCCACGGATGCTAATGAAACTGGTGAGCCTCCGGACCCTGAGCAGCGTCCACTCAGAGCAAGTGTTTGCACTGCGTCTGCAC $\begin{array}{llllllllllllllllllllllllllllll}L & M & F & P & R & M & L & M & K & L & V & S & L & R & T & L & S & S & V & H & S & E & Q & V & F & A & L & R & L & Q\end{array}$ 440

1441 GACAAAAAGCTCCCACCGCTGCTCTCTGAGATCTGGGATGTGCACGAATGACTGTTCTGTCCCCATATTTTCTGTTTTCTTGGCCGGATG

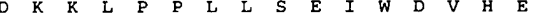

1531 GCTGAGGCCTGGTGGCTGCCTCCTAGAAGTGGAACAGACTGAGAAGGGCAAACATTCCTGGGAGCTGGGCAAGGAGATCCTCCCGTGGCA 1621 TTAAAAGAGAGTCAAAGGGTAAAAAAAAAAAAAAAAAAAAAAAAAAAAAAAAAGGAATTC 1680
Figure 1. Nucleotide and predicted amino acid sequence of human LXR $\alpha$. The upstream in-frame stop codon present in the $5^{\prime}$ UTR is underlined. The predicted start site is at nucleotide 148 ; a putative polyadenylation signal is located at nucleotide position 1620 , and farther downstream at position 1641 is the start of the poly(A) tail. The boxed region indicates the DNA-binding domain. The LXR $\alpha$ cDNA was obtained originally as a fusion to an unrelated haptoglobin cDNA (marked by the arrow) that was artifactually created during cDNA library preparation. Most of this sequence was removed, and the remaining $1680 \mathrm{bp}$ including the full-length LXR $\alpha$ cDNA was subcloned as described in Materials and methods. This sequence has been submitted to GenBank (accession no. U22662). of the LUC reporter gene containing the LXRE /cf. "Control" with "LXR $\alpha$ " in Fig. 4a). Because these results are similar to the activation specificity of $R X R \alpha$, a side-byside comparison of dose responses to 9cRA was performed with $\operatorname{LXR} \alpha$ and RXR $\alpha$ on their respective response elements. As shown in Figure $4 b$, both $L X R \alpha$ and $\mathrm{RXR} \alpha$ show nearly identical, concentration-dependent activation profiles in response to 9cRA. Similar dose responses (not shown) were observed with several other RXR-specific ligands, including LG69 (Boehm et al. 1994). These results suggested the existence of a distinct pathway of gene regulation mediated by LXR $\alpha$ and 9cRA.

\section{Three distinct retinoid response pathways}

To demonstrate that the $\mathrm{LXR} \alpha$ retinoid response is distinguishable from the pathways described previously by the RXR and RAR receptor systems, cotransfection experiments were performed to directly compare the three receptor systems by using receptor-specific ligands and response elements (Fig. 4c-e). For these experiments we used the two retinoid ligands MA and TTNPB, which have been shown previously to be uniquely specific for RXR and RAR, respectively (Mangelsdorf et al. 1990; Kurokawa et al. 1994; Harmon et al. 1995). Expression plasmids for the three receptors $(\mathrm{LXR} \alpha, \mathrm{RXR} \alpha$, and RAR $\alpha$ ) were cotransfected into CV-1 cells along with LUC reporters containing their respective response elements and tested for ligand-dependent activation. In the absence of any response element, the empty reporter plasmid TK-LUC conferred no receptor or ligand-dependent trans-activation (data not shown). However, as also shown above, in the presence of the RXR-specific ligand, MA, LXR $\alpha$ strongly activated transcription from the 
Willy et al.

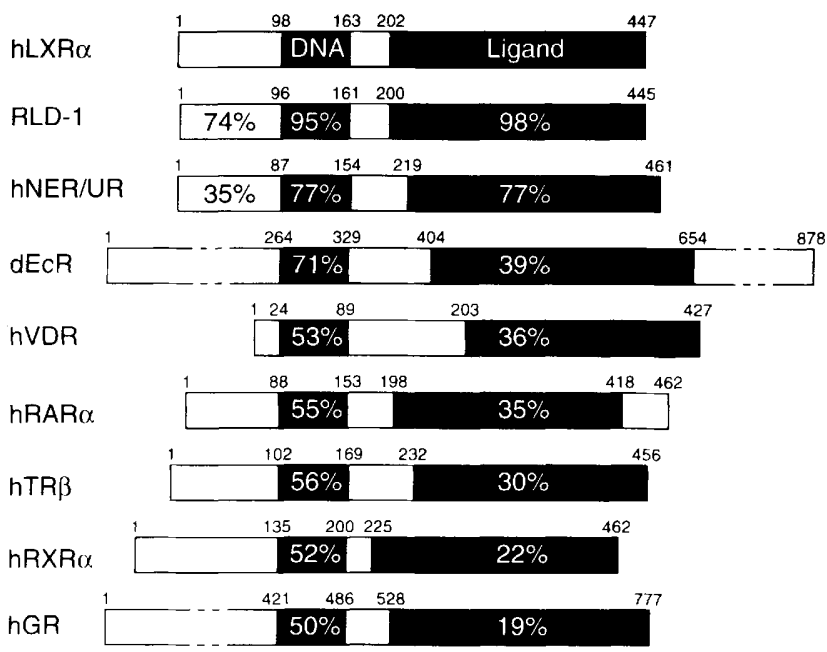

Figure 2. Amino acid sequence comparison between $\mathrm{hLXR} \alpha$ and other members of the nuclear receptor superfamily. Sequence alignments were determined using the University of Wisconsin Genetics Computer Group programs (Devereux et al. 1984). Regions of significant similarity between $h L X R \alpha$ and other receptors are presented schematically as percent amino acid identity. (RLD-1) Rat liver-derived orphan receptor (Apfel et al. 1994); (hNER and hUR) human ubiquitous receptor (Shinar et al. 1994; Song et al. 1994). (dEcR) Drosophila ecdysone receptor (Koelle et al. 1991); (hVDR) human vitamin D receptor (Baker et al. 1988); (hRAR $\alpha$ ) human retinoic acid receptor $\alpha$ (Giguère et al. 1987); (hTRß) human thyroid hormone receptor $\beta$ (Weinberger et al. 1986); (hRXR $\alpha$ ) human retinoid X receptor $\alpha$ (Mangelsdorf et al. 1990); (hGR) human glucocorticoid receptor (Hollenberg et al. 1985).

LXRE-containing reporter (Fig. 4c). In contrast, the RARspecific ligand TTNPB had no effect on the activation of LXR $\alpha$. Significantly, neither $\operatorname{RXR} \alpha$ nor $\operatorname{RAR} \alpha$ was able to substitute for LXR $\alpha$ in mediating LXRE-dependent trans-activation, even in the presence of their cognate ligands.

Figure 4, d and c, demonstrates that the retinoid responsiveness of $L X R \alpha$ is specific to the LXRE and cannot also be mediated through other retinoid response elements. Previously, we identified a retinoid response element from the rat CRBPII promoter that is specific for the RXR homodimer (Mangelsdorf et al. 1991). When this RXR response element (RXRE) is placed into the promoter of the LUC reporter plasmid (TK-CRBPIILUC), there is a marked response to the RXR ligand, MA (Fig. 4d). This response occurs in the presence of $\operatorname{RXR} \alpha$ but not $\operatorname{RAR} \alpha$ or $\operatorname{LXR} \alpha$. It is noteworthy that even though these cells contain low levels of endogenous RXR (see below), the RXR homodimer response requires the transfection of additional RXR. In similar experiments, when a reporter plasmid containing an RAR response element (TK- $\beta$ RE-LUC) is used, the retinoid response is limited to RAR and RXR and their cognate ligands (Fig. $4 \mathrm{e})$. The response to ligand occurs even in the absence of transfected RAR or RXR, confirming the existence of endogenous retinoid receptors, as seen by others (Sucov et al. 1990; Zhang et al. 1992b; Kurokawa et al. 1994). The addition of exogenous $\operatorname{RAR} \alpha$ or $\operatorname{RXR} \alpha$ accordingly increases the respective retinoid response. Importantly, there is no further increase in activation when LXR $\alpha$ is transfected into these cells. These data clearly demonstrate that $\mathrm{LXR} \alpha$ has a retinoid response element specificity that is distinctly unique from RXR and RAR. Furthermore, the $L X R \alpha$ response occurs in the absence of transfected RXR or RAR. Taken together, these results distinguish the human $L X R \alpha$ as a novel mediator of retinoid action.

\section{$L X R \alpha$ forms a functional heterodimer with $R X R \alpha$}

The data presented above suggest two possible explanations to account for the specific activation of $\mathrm{LXR} \alpha$ by retinoids. One possibility is that $L X R \alpha$ is functioning in a fashion similar to other receptors. In this scenario, LXR $\alpha$ trans-activation through an LXRE might be mediated by an LXR homodimer or an RXR/LXR heterodimer in which LXR binds the ligand. However, based on the RXR-like specificity of the retinoid response, another plausible explanation is that $\mathrm{LXR} \alpha$ is not directly bound and activated by these retinoids but instead is an obligatory heterodimeric partner of endogenous RXR and that retinoid binding (and thus trans-activation) requires the presence of RXR. In either case, it is clear that receptor binding and trans-activation through the LXRE is uniquely dependent on the presence of $\operatorname{LXR} \alpha$, because both the RXR homodimer and RXR/RAR heterodimer fail to activate on the LXRE (Fig. 4c).
Figure 3. Northern analysis of LXR $\alpha$ mRNA in adult and embryonic tissue. Ten micrograms of poly $(\mathrm{A})^{+}$RNA from adult rat tissues $|a|$ and mouse embryos (b) from gestation day 9.5 to 18.5 was analyzed in each lane as described in Materials and methods. BRL RNA size markers (in $\mathrm{kb}$ \} are aligned at left. The arrows at right represent the approximate size of LXR $\alpha$-specific transcripts.

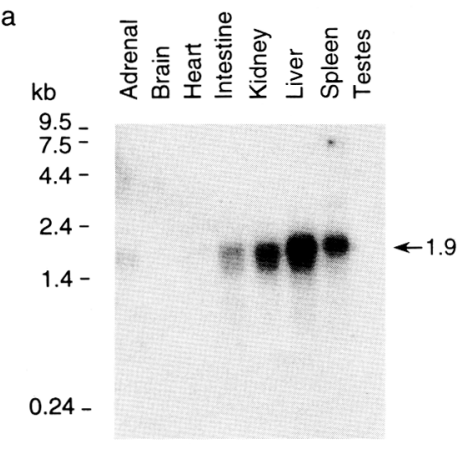

$b$

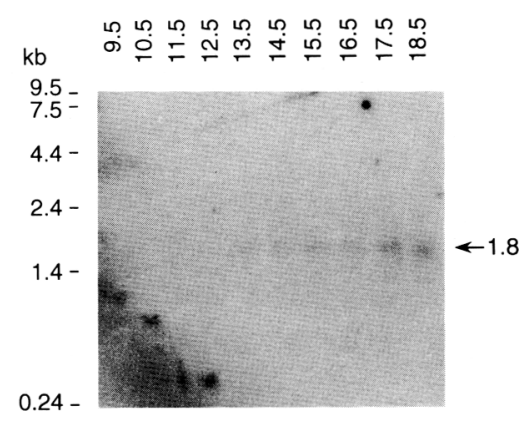


a

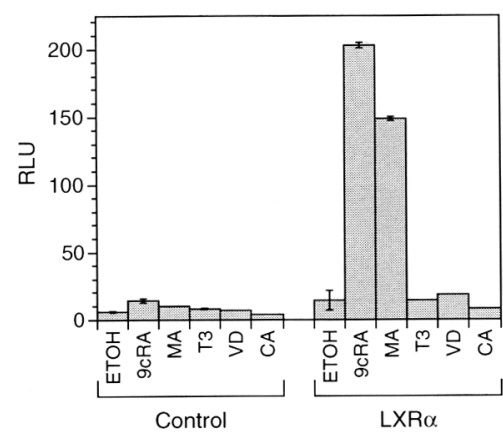

b

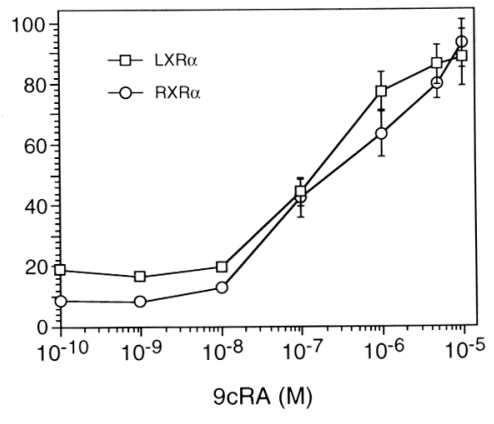

C

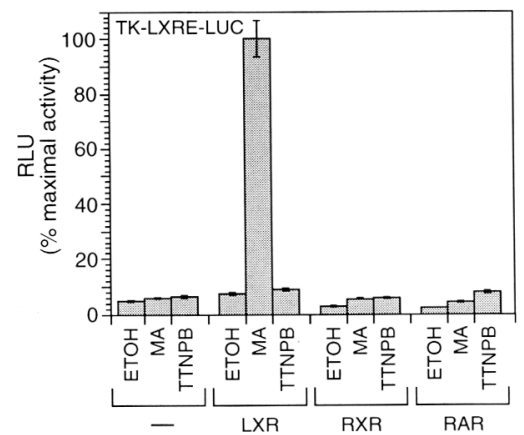

d

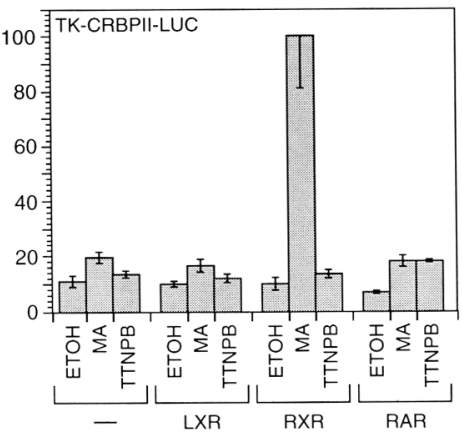

e

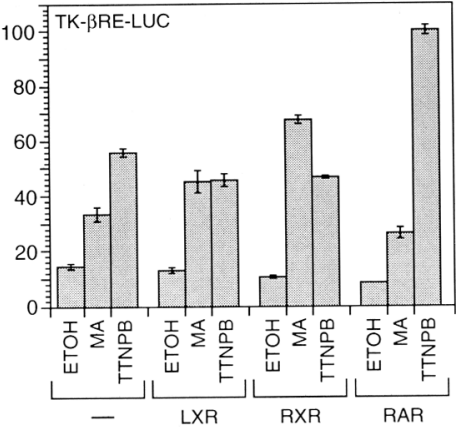

Figure 4. Retinoids specifically induce LXR $\alpha$ on an LXRE. $(a)$ LXR $\alpha$ ligand screen. CV-1 cells were cotransfected with either a control plasmid (Control) or an expression plasmid for hLXR $\alpha$ as indicated in combination with the luciferase reporter plasmid TK-LXRE3LUC and then incubated with various ligands (see below) or an ethanol control (ETOH). (b) LXR $\alpha$ and RXR $\alpha$ dose response to 9-cis retinoic acid. CV-l cells were cotransfected with expression plasmids for hLXR $\alpha(\square)$ or hRXR $\alpha(O)$ and the reporter plasmids TKLXRE3-LUC or TK-CRBPII-LUC, respectively, and then incubated with increasing concentrations of 9cRA. (c-e) LXR $\alpha$, RXR $\alpha$, and RAR $\alpha$ activation by retinoids is response element specific. CV-1 cells were cotransfected with either a control plasmid $|-|$ or expression plasmids for hLXR $\alpha, \mathrm{hRXR} \alpha$, or hRAR $\alpha$ in combination with reporter plasmids TK-LXRE3-LUC $(c)$, TK-CRBPII-LUC $(d)$, or TK- $\beta R E-L U C(e)$ and then incubated with various retinoid ligands (see below) or an ethanol control. TK-LXRE3-LUC contains three copies of the LXRE defined in this work; TK-CRBPII-LUC contains the RXRE from the rat CRBPII promoter (Mangelsdorf et al. 1991); TK- $\beta$ RE-LUC contains the RAR response element from the mouse RAR 32 promoter (Sucov et al. 1990). Luciferase activity is expressed in relative light units (RLU) and represents the mean of triplicate assays ( \pm S.E.M.) normalized to $\beta$-gal as an internal standard. For experiments in $c-e$, we used two different retinoid ligands that have been used previously to distinguish between retinoid receptor systems: $10^{-5} \mathrm{M}$ TTNPB, which is RAR-specific (Mangelsdorf et al. 1990); and 10-4 M MA, which is RXR-specific (Harmon et al. 1995). The concentrations of ligands used in $(a)$ were $10^{-4} \mathrm{M} \mathrm{MA}$ and $9 \mathrm{cRA}, 10^{-6} \mathrm{M}$ thyroid hormone $\left(\mathrm{T}_{3}\right), 10^{-6} \mathrm{M} 1,25-$ dihydroxyvitamin $\mathrm{D}_{3}$ (VD), and $1 \mathrm{~mm}$ clofibric acid (CA).

To test the feasibility of these two hypotheses, we first examined the possibility of a heterodimeric interaction between LXR $\alpha$ and one of the retinoid receptors. For these studies we employed a mammalian version of the two-hybrid system originally described for the detection of protein-protein interactions in yeast (Fields and Song 1989). In this strategy the ligand-binding domain of one receptor (i.e., $L X R \alpha$ ) is fused to the DNA-binding domain of GAL4, creating a hybrid protein (GAL4-LXR $\alpha$; Fig. 5a) that can bind to specific upstream activation sequences $\left(\mathrm{UAS}_{\mathrm{G}}\right)$ but that lacks a constitutive trans-activation domain and therefore cannot by itself activate transcription of a LUC reporter (Fig. 5b). The use of the LXR $\alpha$ ligand-binding domain as the "bait" in these experiments is based on previous studies that have localized a strong dimerization interface in the ligand-binding do- main of other nuclear receptors (Kurokawa et al. 1993; Perlmann et al. 1993). To screen for receptors that may interact with LXR $\alpha$, the candidate receptors were fused to the 78-amino-acid trans-activation domain of VP16. Each VP16-receptor chimera (Fig. 5a) was cotransfected along with GAL4-LXR $\alpha$ into CV-1 cells (Fig. 5b). In the presence of two receptors capable of dimerization, the VP16 trans-activation domain is brought into functional proximity with the GAL4 DNA-binding sequences, which in turn permits activation of the promoter driving LUC expression. As is clearly demonstrated in Figure 5b, only the VP16 hybrid protein containing RXR $\alpha$ (but not RAR $\alpha$ ) is able to induce transcription in the presence of GAL4-LXR $\alpha$. Similar VP16 hybrids of the VDR and TRs are unable to confer trans-activation (T. Perlmann, unpubl.). These experiments demonstrate a specific inter- 
Willy et al.

a

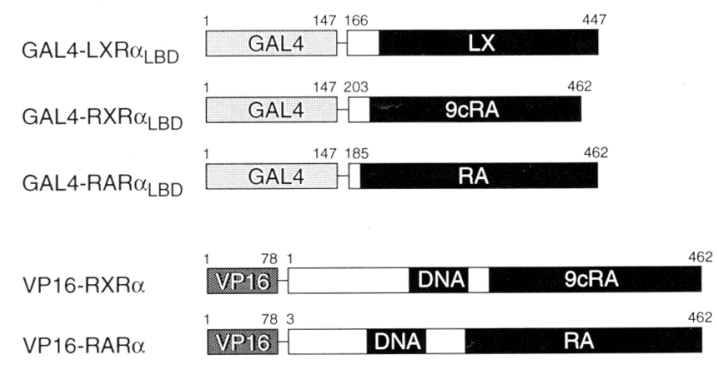

b

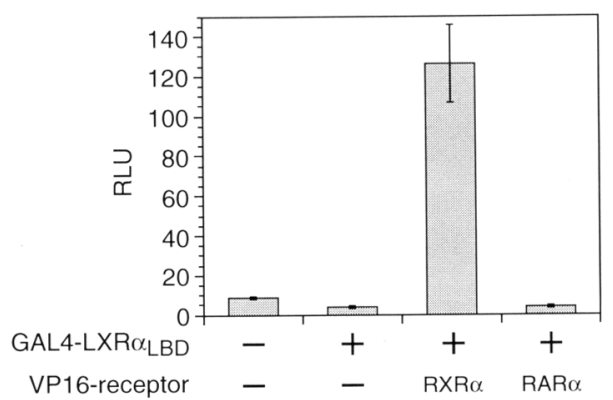

C
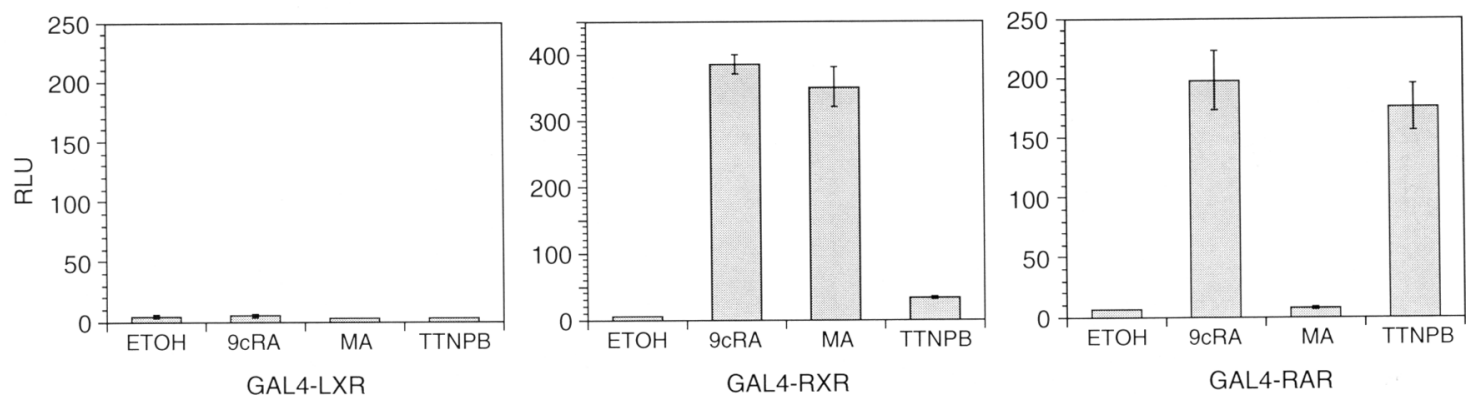

Figure 5. The putative ligand-binding domain of LXRa contains a functional, RXR-specific heterodimerization domain but not a functional retinoid-binding domain. (a) Schematic representation of GAL4 and VP16 hybrid proteins used in these experiments. The amino acid sequences from each parent protein used to construct the hybrid receptors are shown at the top. For details on construction see Materials and methods. (b) Trans-activation of GAL4-LXR $\alpha$ requires the presence of VP16-RXR $\alpha$ but not VPl6-RAR $\alpha$ in the mammalian two-hybrid system. In negative control experiments (not shown), none of the VP16 receptors alone are able to confer trans-activation. (c) Ligand specificity of the GAL4-receptor chimeras demonstrates that retinoid responsiveness can be conferred through the ligand-binding domains of RXR and RAR but not LXR. In $b$ and $c$, CV-l cells were cotransfected as described in Materials and methods with CMX vectors driving expression of the indicated hybrid proteins and the reporter plasmid TK-MHI00x4-LUC, which contains four copies of the GAL4 DNA upstream activation sequence (Kang et al. 1993). In $c$ ligands were added as described in Fig. 4 except 9cRA was added at $10^{5} \mathrm{M}$. Luciferase activity is expressed as a function of RLUs corrected for transfection efficiency using an internal $\beta$-gal standard and represents the mean of triplicate assays $( \pm$ S.E.M.).

action between $\mathrm{LXR} \alpha$ and $\mathrm{RXR} \alpha$ and provide strong evidence that these two receptors form a functional heterodimer in vivo.

\section{GAL4-receptor hybrids define ligand-binding specificity}

To address the possibility that the retinoid response elicited by $\operatorname{LXR} \alpha$ is through the direct interaction of ligand with the putative ligand-binding domain of $\operatorname{LXR} \alpha$, we performed ligand activation experiments with the GAL4-receptor hybrids. Previous studies have shown that the ligand-binding domains of nuclear receptors contain ligand-dependent activation domains (Nagpal et al. 1992). Thus, when a nuclear receptor ligand-binding domain is fused to the DNA-binding domain of GAL4, this hybrid transcription factor alone can confer liganddependent trans-activation of a $\mathrm{UAS}_{\mathrm{G}}$-containing reporter (Nagpal et al. 1993). Such a heterologous system provides an effective means for directly assaying receptor-ligand interactions even in the presence of endoge- nous wild-type receptors. As shown in Figure $5 c$, the chimeric receptors GAL4-RXR and GAL4-RAR confer ligand-inducible trans-activation that accurately mimics the cognate ligand specificity of wild-type receptor proteins: 9cRA activates both RXR and RAR, MA only activates $R X R$, and TTNPB specifically activates RAR. In contrast, no activation is seen with the GAL4-LXR chimera in the presence of these same ligands. These results indicate that retinoid receptor ligands cannot directly interact with the LXR $\alpha$ ligand-binding domain when evaluated under similar conditions that permit their interaction with RXR and RAR. Furthermore, the specificity of 9cRA and MA for RXR, taken together with the heterodimerization studies, are strong evidence that the $\mathrm{LXR} \alpha$ retinoid response requires the presence of $\mathrm{RXR} \alpha$.

\section{$L X R / R X R$ heterodimers bind and activate through the LXRE}

The previous experiments suggest the existence of an LXR/RXR heterodimer as the mediator of retinoid sig- 
naling through a unique retinoid response element, referred to as the LXRE. We originally identified this element in the $5^{\prime}$ regulatory region of $\triangle \mathrm{MTV}$ (Hollenberg and Evans 1988), a promoter derived from the mouse mammary tumor virus LTR in which the glucocorticoid response elements have been deleted. $\triangle \mathrm{MTV}$ is used routinely in conjunction with heterologous response elements to drive receptor-specific expression of reporter genes (Hollenberg and Evans 1988). In the context of the reporter gene $\triangle M T V-L U C, L X R \alpha$ elicited retinoid-dependent trans-activation (data not shown) similar to that seen in Figure 4. Deletion mutagenesis of the $\triangle M T V$ promoter identified a region of 30 nucleotides (Fig. 6a) that when transferred to the TK-LUC vector confers full LXR $\alpha$ activation by retinoids (Fig. 4). As has been shown to be the case with all other nuclear receptor response elements, increasing the number of LXREs in the reporter plasmid coincidentally increases hormone responsiveness (not shown).

To test whether this sequence was specifically bound by an LXR/RXR heterodimer, electrophoretic mobilityshift assays were performed using in vitro-synthesized receptor proteins and ${ }^{32} \mathrm{P}$-labeled LXRE probe (Fig. $6 \mathrm{~b}$ ). LXR $\alpha$ and RXR $\alpha$ do not bind to the LXRE probe individually (Fig. 6b, lanes 2,3), but when mixed together, a strong protein-DNA complex is formed (lane 4). This complex is supershifted in the presence of $\mathrm{RXR} \alpha$-specific antisera (Fig. 6b, lane 5) but not in the presence of a nonspecific antisera (lane 6). These results are consistent with the conclusion that only the LXR/RXR heterodimer is capable of high-affinity binding to the LXRE. To demonstrate the functionality of the LXR/RXR hetero- dimer, an experiment was performed by cotransfecting both LXR $\alpha$ and RXR $\alpha$ with the LXRE reporter in the presence of the RXR-specific ligand MA (Fig. 6c). As was also demonstrated in Figure 4c, the addition of LXR $\alpha$ alone gives a marked ligand response, whereas $\mathrm{RXR} \alpha$ alone gives no response. However, when both LXR $\alpha$ and $\mathrm{RXR} \alpha$ are added together, there is a dramatic synergistic increase in both basal and retinoid responsive activities. The LXR/RXR heterodimer must be exquisitely sensitive to retinoid, because under the conditions these experiments were performed (Fig. 6c), even the addition of one-tenth the amount of RXR $\alpha$ (compared with LXR $\alpha$ ) expression plasmid greatly increases the LXR-dependent response. From these experiments we conclude that the presence of endogenous RXR in these cells (Titcomb et al. 1994) is responsible for the ability of LXR $\alpha$ when added alone to confer retinoid responsiveness. This conclusion is consistent with the ability of endogenous RXR to also function as a heterodimeric partner for RAR and other nuclear hormone receptors. The important difference in this case is that RXR does not play the role of a silent partner but rather takes on the role of the active, ligand-binding receptor partner. To our knowledge this is the first report of an instance where endogenous RXR is capable of functioning as a potent retinoid receptor on an element where it acts exclusively as a heterodimer.

\section{The LXRE is a novel DR4 retinoid response element}

It has been shown previously that the heterodimers formed between RXR and other nuclear receptors can a

LXRE: CTTGCGGTTCCCAGGGTTTAAATAAGTTCA

b

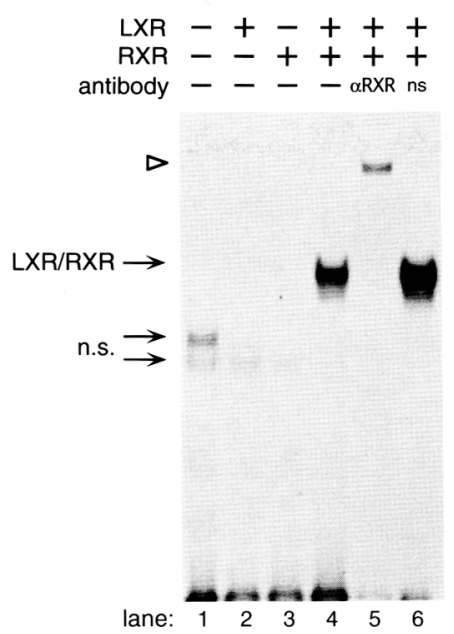

C

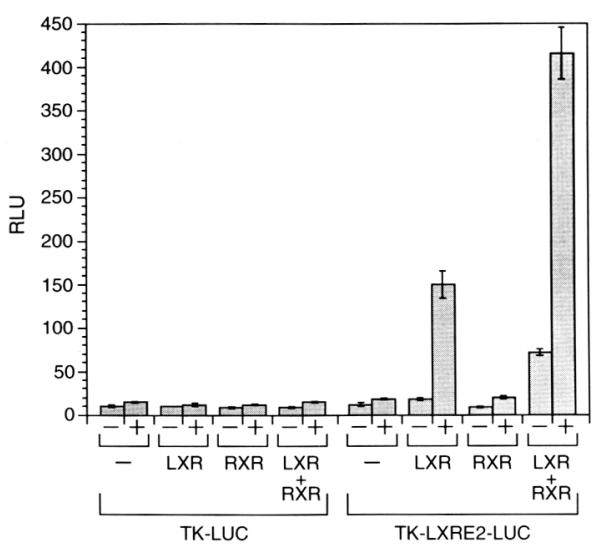

Figure 6. The LXRE is a functional, highaffinity binding site for LXR/RXR heterodimers. (a) Sequence of the LXRE initially identified at positions -123 to -94 from the transcription start site in the $\triangle \mathrm{MTV}$ promoter (Hollenberg and Evans 1988). Arrows indicate potential response element half-sites. $(b)$ LXR $\alpha$ binds to the LXRE as an RXR heterodimer. Gel mobility-shift assays were performed as outlined in Materials and methods. The ${ }^{32} \mathrm{P}$-labeled LXRE oligonucleotide was incubated with in vitro-synthesized $\mathrm{LXR} \alpha$ and/or RXR $\alpha$ proteins as indicated in the presence or $\mathrm{ab}$ sence of anti-RXR $\alpha$ antibody $(\alpha \mathrm{RXR})$ or a nonspecific antibody (ns). The positions of the LXR/RXR heterodimer, antibody supershifted LXR/RXR (arrowhead), and nonspecific (n.s.) complexes are shown. $(c)$ $\mathrm{RXR} \alpha$ synergistically increases $\mathrm{LXR} \alpha$ responsiveness to retinoids. Expression plasmids for $h L X R \alpha, h R X R \alpha$, or no receptor $1-\mid$ were cotransfected into CV-1 cells in combination with the reporter plasmids TK-LUC or TK-LXRE2-LUC as indicated. Cells were then incubated with ethanol control $\left(-\mid\right.$ or $10^{-4} \mathrm{M} \mathrm{MA}(+)$ and assayed for luciferase activity as described in Fig. 4 . TK-LXRE2-LUC contains two copies of the LXRE. In experiments in which LXR and RXR plasmids were cotransfected together, the ratio of the two expression plasmids was 1:0.1 (25 ng of $h L X R \alpha$ to $2.5 \mathrm{ng}$ of $h R X R \alpha$ ). In all other experiments where $L X R$ and $R X R$ were added alone, the amount of each receptor expression plasmid was $25 \mathrm{ng}$. 
bind and activate through DNA response elements that are direct repeats of the core sequence AGGTCA spaced by $1-5$ nucleotides (designated as DR 1, DR2, DR3, DR4, and DR5) (for review, see Giguère 1994; Kastner et al. 1994b; Mangelsdorf et al. 1994). Inspection of the LXRE sequence in Figure 6a reveals the presence of two degenerate hexad sequences (underscored by arrows) spaced by 4 nucleotides that resemble the canonical direct repeat. The configuration of the LXRE into a putative direct repeat spaced by 4 nucleotides (i.e., DR4) was examined by performing a competition analysis with 10 different mutant LXRE oligonucleotides in which pairs of nucleotides were systematically changed to cytosine $(C)$ or guanine $(G)$ in the region within and flanking the DR4 motif (Fig. 7a). The ability of mutant LXREs to compete with the labeled native LXRE probe was analyzed using the gel mobility-shift assay. Figure 7a shows that mutant oligonucleotides with substitutions within either half-site of the DR4 motif fail to compete with native LXRE for binding to the LXR/RXR heterodimer even at 50-fold molar excess (lanes 3-8, 13-18). In contrast, LXRE oligonucleotides with similar substitution mutations in the spacer and flanking regions are able to compete well for binding to the LXR/RXR heterodimer (Fig. 7a, lanes 1,2,9-12,19-20). Furthermore, the introduction or subtraction of a single nucleotide into the spacer region of the LXRE to create a DR5 or DR3 motif, respectively, resulted in oligonucleotides that fail to competitively
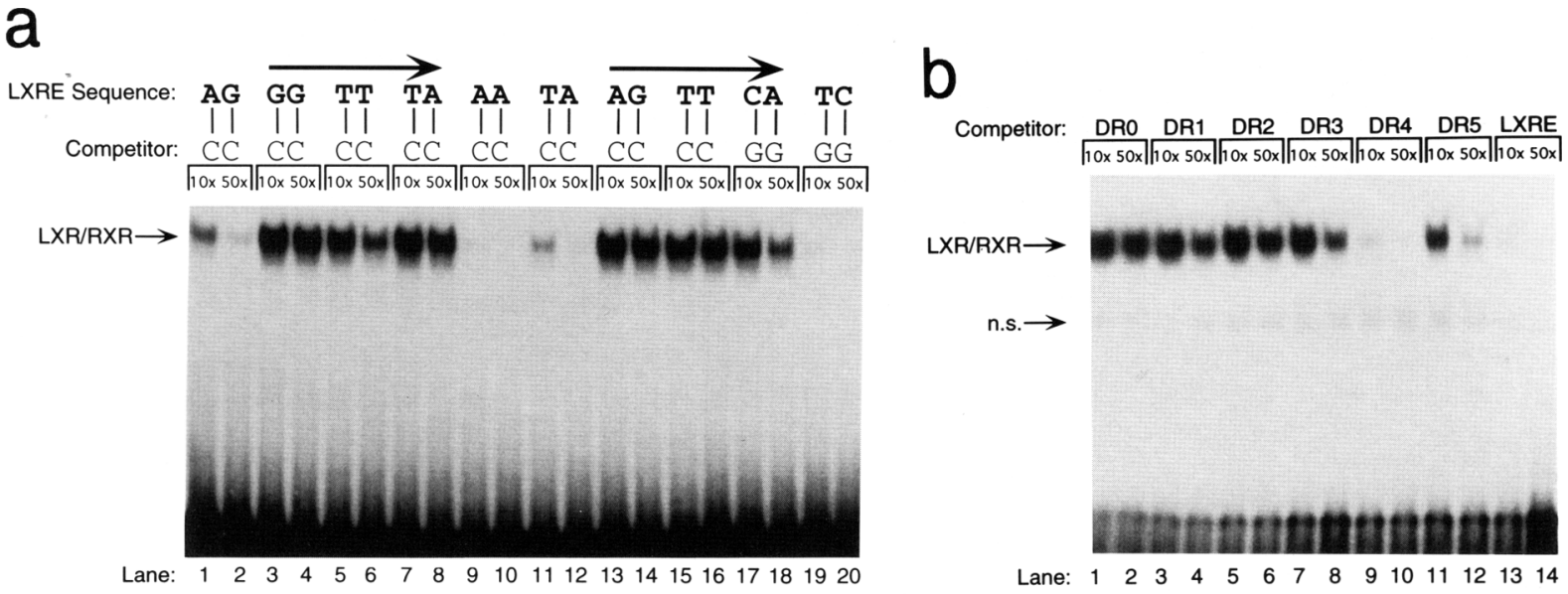

C

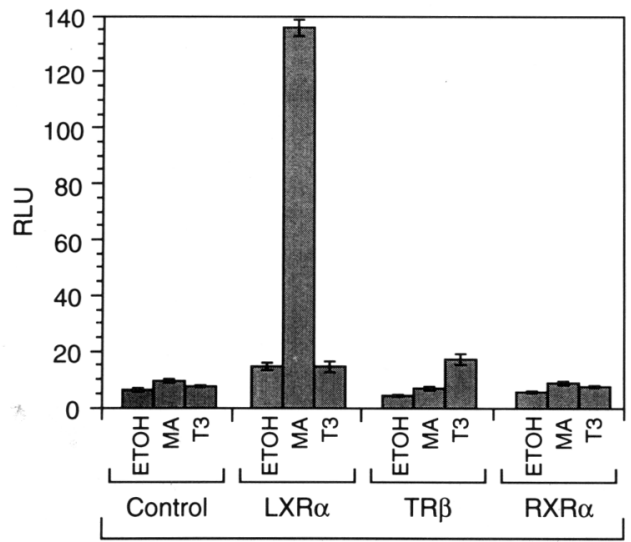

TK-LXRE3-LUC

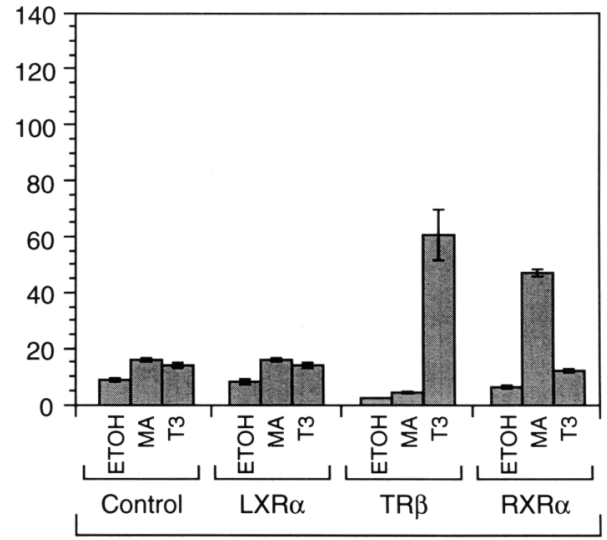

TK-DR4×2-LUC

Figure 7. The LXR/RXR heterodimers bind to DR4 response elements. (a) The LXRE is a DR4-like sequence. Competition gel mobility-shift assays were performed as described in Materials and methods using in vitro-synthesized LXR $\alpha$ and RXR $\alpha$ proteins, ${ }^{32}$ P-labeled LXRE as input probe, and unlabeled LXRE mutant oligonucleotides as competitors at 10- and 50-fold molar excesses. Each of the 10 competitor mutant oligonucleotides differ by 2 base substitutions from the wild-type LXRE at the positions indicated at the top. (b) LXR/RXR heterodimers bind specifically to canonical DR4 sequences. Competition mobility-shift assays were performed as in $a$, except that competitor oligonucleotides were perfect tandem repeats (DR0-DR5) of the sequence AGGTCAnAGGTCA, where $n=0-5$ spacer nucleotides (Kliewer et al. 1992b). Competition with the natural LXRE is shown as a positive control. (c) Transactivation of $L X R \alpha, T R \beta$, or RXR $\alpha$ on an LXRE (TK-LXRE3-LUC) or a canonical DR4 response element (TK-DR4x2-LUC) reporter. Like the canonical DR4 element, other known DR4 thyroid hormone response elements also demonstrate high-affinity LXR $\alpha$ binding but are not retinoid responsive (not shown). Cotransfections and luciferase assays were performed as in Fig. 4; ligands were added at $10^{-4} \mathrm{M}$ MA or $10^{-6} \mathrm{M}$ thyroid hormone $\left(\mathrm{T}_{3}\right)$. Luciferase activity is expressed in RLUs ( \pm S.E.M. of triplicate assays). 
bind or be activated by the LXR/RXR heterodimer (data not shown).

From the data presented above, it appears that the minimal LXRE is a DR4-type response element. To further investigate this possibility, a series of perfect AGGTCA direct repeat oligonucleotides spaced by $0-5 \mathrm{nu}$ cleotides (DR0, DR1, DR2, DR3, DR4, and DR5) were used to compete with labeled LXRE for binding the LXR/ RXR heterodimer. Figure $7 \mathrm{~b}$ shows that only the DR4 oligonucleotide (lanes 9,10 ) can compete comparably to the LXRE (lanes 13,14) for binding to LXR/RXR even at a 10-fold molar excess. Because DR4 sequences are known to bind RXR/TR heterodimers and function as potent thyroid hormone response elements, it was of interest to know if LXR $\alpha$ could also activate through these DR4 elements. As shown, LXR $\alpha$ activation is specific only to the LXRE (Fig. 7c, left) and is not functional on a canonical DR4 thyroid hormone response element (Fig. $7 \mathrm{c}$, right). In independent experiments, we have also demonstrated that the LXR/RXR can bind but is completely inactive on several other DR4 elements that are known to be thyroid hormone responsive as well. Interestingly, the LXRE is reciprocally a very poor thyroid hormone response element (Fig. 7c, left), in spite of the fact that the RXR/TR heterodimer binds to this sequence with high affinity (data not shown). These experiments suggest that DNA binding alone is insufficient to permit trans-activation. Thus, the LXRE represents a novel DR4 motif that can distinguish between two hormonal pathways.

\section{Discussion}

RXRs are unique in their ability to function as both homodimeric receptors and as obligate heterodimeric partners to receptors in multiple hormone response pathways. The central role of RXR in these pathways is summarized in Figure 8. In the retinoic acid response pathway, as a heterodimer, RXR does not bind ligand but rather serves as a cofactor to RAR in preferentially activating target genes containing DR5 response elements. As a homodimer, the ability of RXR to bind ligand and function exclusively as a 9cRA receptor is limited to DR1-containing target genes. Thus far, activation through the RXR homodimer has been shown to be dependent on the artificial overexpression of RXR, because in all cell types tested, the ubiquitous endogenous expression of RAR and RXR leads to the preferential formation of heterodimers that prevent RXR from binding ligand. This apparent lack of target cells in which the expression of RAR is sufficiently lower than RXR to allow formation of RXR homodimers raises the question as to whether RXR can function in vivo as a 9cRA receptor. In spite of these findings, there is now good evidence that retinoid signaling through RXR can occur in vivo and in cells where both RAR and RXR are naturally expressed (Davis et al. 1994). Taken together, these results suggest the existence of an alternative pathway

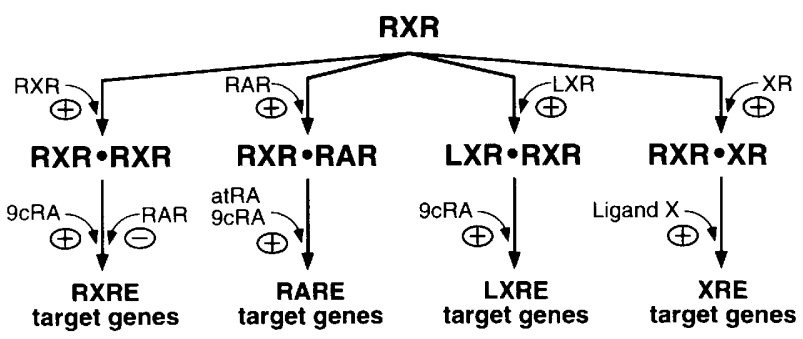

Figure 8. RXR signaling pathways. As a dimer partner, RXR is a master regulator of multiple hormone-response pathways, including at least three that are retinoid responsive: (1) The RXR homodimer binds and is responsive to 9cRA on DRl target gene elements (RXREs). This response is strongly repressed by RAR, which preferentially heterodimerizes with RXR. The interaction with RAR prevents RXR from binding ligand (Kurokawa et al. 1994) but forms a high-affinity complex on the RXRE that is transcriptionally inactive (Mangelsdorf et al. 1991). Thus, for RXR to respond to ligand, the ratio of RXR to RAR in a cell must be very high. (2) As a heterodimer, RXR does not bind ligand (Kurokawa et al. 1994) but functions as a silent partner to RAR in mediating atRA and 9cRA responses through RAREs composed of DR5 (and presumably DR2) sequences. (3) As illustrated in this work, the orphan receptor LXR $\alpha$ defines a third 9cRA response pathway in which RXR participates as the active ligand-binding partner. The LXR/RXR heterodimer responds to retinoid through a specific DR4-like element (the LXRE). Unlike the RXR response on a DR1 element, the LXR/RXR response is uniquely sensitive to 9cRA and can function potently in the presence of the low levels of endogenous RXR in the cell. (4) RXR also subserves the role of heterodimeric partner to several other receptor systems (designated by XR), including vitamin $\mathrm{D}$, thyroid hormone, and peroxisome proliferators.

that allows RXR to function in vivo as a 9cRA receptor. In this paper we have identified the orphan receptor $\mathrm{LXR} \alpha$ as a tissue-specific cofactor that permits RXR to function as a potent $9 \mathrm{cRA}$ receptor with a distinct target gene specificity. The LXR effect is mediated through a unique heterodimeric interaction, which switches the role of RXR from a silent partner to an active, ligandbinding partner in the heterodimer complex. Significantly, this finding establishes a new pathway by which RXR can function as a bona fide receptor, and further, it defines a third retinoid response system with a novel target gene specificity.

Unlike the RXR homodimer, the LXR/RXR heterodimer response to 9cRA in cells can occur in the presence of endogenous RXR and RAR. In the context of the LXR/ RXR heterodimer, the mechanism of RXR activation by ligand appears to be similar to that of RAR: Both receptors require a partner for specific DNA binding and ligand activation. The nature of the LXR/RXR heterodimer, however, is unique in several respects. The heterodimerization of LXR and RXR is specific; we can find no evidence of an LXR interaction with other receptors. Furthermore, the LXR/RXR heterodimer binds to a variety of DR4-like elements but thus far is only ligand responsive on the LXRE. This finding indicates that 
DNA binding alone is not sufficient for ligand inducibility. Recent studies have shown that the polarity of the RXR/RAR heterodimer on the DR5 element is such that RXR sits on the $5^{\prime}$ half-site and RAR on the $3^{\prime}$ half-site (Kurokawa et al. 1993; Perlmann et al. 1993). In this configuration RAR can bind and respond to ligand. However, on a DRl element, the polarity of the RAR/RXR heterodimer is reversed and although $R A R$ retains its ability to bind ligand, the complex is no longer ligand responsive (Kurokawa et al. 1994). By analogy, these results suggest that the configuration of the LXR/RXR heterodimer on an LXRE may be different than on other response elements. Thus, it will be of interest to determine the DNA-binding polarity of the LXR/RXR heterodimers in future studies. In addition, we are currently in the process of determining the optimal LXRE sequence for activation by retinoids to facilitate the search for potential target genes. The coincident expression pattern of $\mathrm{LXR} \alpha$ and $\mathrm{RXR} \alpha$ suggests that these genes may have a role in adult physiology as was originally predicted for RXR $\alpha$ (Mangelsdorf et al. 1990).

While this work was in progress, two other groups reported orphan receptors that by sequence comparison are related to LXR $\alpha$ (Apfel et al. 1994; Song et al. 1994). Although it is not known whether these orphan receptors can also direct an RXR ligand response on an LXRE, they are able to heterodimerize with RXR and bind to DR4 response elements. The finding of a potential family of LXRs would establish a mechanism by which the pleiotropic effects of retinoids could be broadened to encompass an entirely new class of genes.

One fundamental question in the field of nuclear hormone receptors is the function of the ever increasing subclass of this protein family that has been referred to as orphan receptors. Although activators for these potential ligand-dependent transcription factors are unknown, their remarkable similarity to other nuclear receptors suggests that they may have ligands and operate in a fashion similar to the known receptors. Thus far, our data support the notion that it is RXR and not LXR that binds the ligands used in these studies. It is also possible that the LXR/RXR heterodimer has unique ligand-binding properties that are different than either of the receptors alone, as is the case for the functional ecdysone receptor complex (Yao et al. 1993). Whether LXR also has a ligand is clearly an important area for further study. However, studies on both the known and orphan receptors have revealed that many of these proteins have transcription-modulating activity that may be considered ligand-independent. As demonstrated previously for RXR and as shown here for LXR, these receptors can subserve important ligand-independent functions as obligate dimer partners. From these findings it might be predicted that other orphan receptors exist that may serve similar roles, some of which are likely to intersect the retinoid response system. Although the discovery of LXR provides another layer to the already daunting complexity of retinoid action, we note that the one common thread in retinoid signaling continues to be the presence of RXR.

\section{Materials and methods}

Molecular cloning and analysis of LXR CDNAs

The KpnI-SacI restriction fragment $(503 \mathrm{bp}$ ), including the DNA-binding domain of hRAR $\alpha$ was used to screen a $\lambda g t 11$ human liver cDNA library at low stringency as described previously (Mangelsdorf et al. 1990). Positive clones were isolated, subcloned into pGEM vectors (Promega), restriction mapped, and sequenced by the dideoxy method with Sequenase (U.S. Biochemical) using both single-stranded and double-stranded DNA templates. Sequences were aligned and analyzed by the University of Wisconsin Genetics Computer Group programs (Devereux et al. 1984). Several LXR clones were isolated; the longest, designated $\lambda H L 1-1$, contained a $2.8-\mathrm{kb}$ insert that was subsequently subcloned into the EcoRI site of pBluescript - KS (Stratagene). Because the size of this insert was identical to that of the vector and contained $\sim 1.2 \mathrm{~kb}$ of $5^{\prime}$ sequence that appears to be unrelated to the LXR CDNA (see Fig. 1), the first 1151 nucleotides of this clone were excised by EcoRV digestion at two restriction sites, one within the insert and the other in the multiple cloning site of the vector. The resultant DNA was religated and named pXR2 $\triangle \mathrm{RV}$. The putative cDNA insert of pXR2 $2 \Delta R V$ is 1680 bp (see Fig. 1) and contains the entire coding region of hLXR $\alpha$ as well as a potential polyadenylation signal sequence and 33 bases of the poly $(A)^{+}$tail.

\section{Plasmids}

Constructions of wild-type receptors inserted into the expression vectors RSV and CMX have been detailed elsewhere (Giguère et al. 1986; Mangelsdorf et al. 1990; Umesono et al. 1991). The hLXR $\alpha$ cDNA insert was excised from the plasmid pXR2 $2 \Delta \mathrm{RV}$ with $K p n I$ and $B a m H I$ and was ligated into the expression vectors RSV and CMX. Chimeric GAL4-receptor expression plasmids (e.g., CMX-GAL4-LXR $\alpha$ ) were constructed by first ligating the GAL4 portion of pSG424 (Sadowski and Ptashne 1989) into the HindIII-SacI sites of pCMX (Umesono et al. 1991/ to create pCMX-GAL4. This vector contains the CMV promoter fused to the coding sequence for GAL4|1-147), followed by in-frame polylinker cloning sites and translational stop codons. The cDNAs encoding the ligand-binding domain (LBD) of each of the receptors were then ligated into the polylinker to create GAL4-LBD fusions. The following receptor amino acid sequences were used for these constructions, and their corresponding DNA sequences were ligated into pCMXGAL4: hLXR $\alpha$ 166-447, hRXR $\alpha$ 203-462, and hRAR $\alpha$ 186-462. Likewise, chimeric VP16-receptor expression plasmids were constructed by fusing the cDNA fragment encoding the 78amino-acid trans-activation domain of VP16 (Triezenberg et al. 1988 | in-frame to the cDNA encoding the desired nuclear receptor. The VP16-receptor fusions were engineered into CMX expression plasmids. Each chimera contains a 6- to 12-aminoacid linker at the VP16-receptor fusion point to facilitate an in-frame junction. Kozak translational start sites (CACCATGG) were engineered into the $5^{\prime}$ end of the VPl6-receptor chimeras to provide strong initiator methionines. All fusion points and cloning sites were sequenced, and the full-length proteins were in vitro-synthesized to ensure sequence fidelity. Reporter plasmids for these studies were constructed by ligating the appropriate oligonucleotides into the HindIII site of the TKLUC vector to create TK-LXRE-LUC, TK-MH100x4-LUC (Kang et al. 1993), TK-DR4x2-LUC (Umesono et al. 1991), TKCRBPII-LUC (Mangelsdorf et al. 1991), and TK- $\beta$ RE-LUC (Sucov et al. 1990). The sense strand of the LXRE oligonucleotide used to construct the reporter plasmids was 5'-agcttGCGGT- 
TCCCAGGGTTTAAATAAGTTCATCTAGAT-3', All constructs were verified by sequencing.

\section{Cell culture and cotransfection assays}

$\mathrm{CV}-1$ cells were maintained at $37^{\circ} \mathrm{C}, 5 \% \mathrm{CO}_{2}$ in DMEM containing $5 \%$ calf bovine serum (CBS). Transfections were performed in 48 -well plates in media containing $5 \%$ dextran-charcoal-stripped CBS by the calcium phosphate coprecipitation technique as described previously (Mangelsdorf et al. 1990). Eight hours after transfections, ligands were delivered to cells at $10^{3}$-fold dilutions $[0.1 \%(\mathrm{vol} / \mathrm{vol})$ of solvent in media]. Retinoids (gifts from Marcus Boehm, Ligand Pharmaceuticals, Inc., San Diego, CA) were manipulated under gold light and stored dark in ethanol or methanol under nitrogen gas at $-80^{\circ} \mathrm{C}$. Cells were harvested $36 \mathrm{hr}$ after addition of ligand and analyzed for luciferase and $\beta$-galactosidase activity using a Dynatech microtiter plate model ML3000 luminometer and a model MR5000 spectrophotometer, respectively. For most experiments, cotransfection of DNA into mammalian cells was accomplished with $50 \mathrm{ng}$ of reporter plasmid, $50 \mathrm{ng}$ of RSV- $\beta$ gal or CMX-ßgal, $25 \mathrm{ng}$ of each receptor expression plasmid, and pGEM carrier to give $375 \mathrm{ng}$ of DNA/well. For controls, the empty CMX vector was used in place of the receptor $\mathrm{CDNA}$. For the GAL4-receptor chimera experiments, $30 \mathrm{ng}$ of receptor and $80 \mathrm{ng}$ of reporter plasmid were used. For GAL4 and VPl 6 chimera interaction assays, $30 \mathrm{ng}$ of GAL4-LXR $\alpha$ and $15 \mathrm{ng}$ of the VP16-RAR or VP16-RXR were used along with $80 \mathrm{ng}$ of the reporter plasmid. All transfection data points were normalized using an internal $\beta$-galactosidase marker (Mangelsdorf et al. 1990 ) and represent the mean of duplicate or triplicate assays.

\section{Northern analysis}

Murine poly(A)' RNA used in these studies was prepared and assayed by Northern analysis as described previously (Mangelsdorf et al. 1992). Equal amounts $(10 \mu \mathrm{g})$ of poly(A) ${ }^{+}$RNA were loaded in each lane and verified by ethidium bromide staining. The DNA hybridization probe used on each blot was the 534-bp EcoRI fragment of the pXR $2 \Delta \mathrm{RV}$ cDNA insert. This probe includes nucleotides $1147-1680$ of the hLXR $\alpha$ cDNA and encodes part of the ligand-binding domain and 3 ' UTR of the clone. Autoradiography was for 2 days at $-70^{\circ} \mathrm{C}$ with intensifying screens.

\section{Electrophoretic mobility-shift assays}

For electrophoretic mobility-shift assay (EMSA) experiments, receptor proteins were generated using a coupled in vitro transcription/translation system according to the manufacturer's instructions (Promega). Sequences of double-stranded oligonucleotides were as shown in the figures and text and were synthesized with HindIII overhangs. Binding reactions were performed in a total volume of $20 \mu \mathrm{l}$ consisting of $75 \mathrm{~mm} \mathrm{KCl}, 20$ mM HEPES at pH 7.4, 2 mM DTT, 7.5\% glycerol, $0.1 \%$ NP-40, $2 \mu \mathrm{g}$ of poly[d(I-C) (Pharmacia), 40 pmoles of a nonspecific single-stranded oligonucleotide (for removal of nonspecific binding in the lysates), and $2 \mu \mathrm{l}$ of receptor lysates or unprogrammed (control) lysates. Reactions containing lysates and competing oligonucleotides were incubated for $30 \mathrm{~min}$ on ice followed by the addition of 40 fmoles of ${ }^{32} \mathrm{P}$-labeled oligonucleotide probe (labeled by end-filling) and further incubated for 20 min at room temperature. Samples were then analyzed on $5 \%$ polyacrylamide gels run in $0.5 \times$ TBE buffer. For antibody supershifting experiments, $1 \mu \mathrm{l}$ of anti-hRXR $\alpha$ antiserum (a gift from Jacki Dyck, The Salk Institute, San Diego, CA) or nonspe- cific antiserum was added to the reactions after addition of the radiolabeled probe and incubated at room temperature for 10 min, followed by gel electrophoresis.

\section{Acknowledgments}

We thank Nasir Sadatyar for technical assistance; Drs. Bruce Blumberg, Pundi Rangarajan, and Barry Forman for the GAL4/ VP16 expression and reporter plasmids; and Drs. Steve Kliewer and Thomas Perlmann for sharing unpublished data. We thank members of the Mango lab for critical discussions. D.J.M. and R.M.E. are investigators of the Howard Hughes Medical Institute (HHMI) at the University of Texas Southwestern Medical Center and The Salk Institute, respectively. K.U. was a staff scientist at The Salk Institute. This work was supported by HHMI (D.J.M. and R.M.E.), a National Institutes of Health (NIH) Shannon award to D.J.M. and an NIH Pharmacological Sciences Training Grant to P.J.W.

The publication costs of this article were defrayed in part by payment of page charges. This article must therefore be hereby marked "advertisement" in accordance with 18 USC section 1734 solely to indicate this fact.

\section{References}

Allegretto, E.A., M.R. McClurg, S.B. Lazarchik, D.L. Clemm, S.A. Kerner, M.G. Elgort, M.F. Boehm, S.K. White, J.W. Pike, and R.A. Heyman. 1993. Transactivation properties of retinoic acid and retinoid $X$ receptors in mammalian cells and yeast. Correlation with hormone binding and effects of metabolism. I. Biol. Chem. 268: 26625-26633.

Apfel, R., D. Benbrook, E. Lernhardt, M.A. Ortiz, G. Salbert, and M. Pfahl. 1994. A novel orphan receptor specific for a subset of thyroid hormone-responsive elements and its interaction with the retinoid/thyroid hormone receptor subfamily. Mol. Cell. Biol. 14: 7025-7035.

Baker, A.R., D.P. McDonnell, M. Hughes, T.M. Crisp, D.J. Mangelsdorf, M.R. Haussler, J.W. Pike, J. Shine, and B.W. O'Malley. 1988. Cloning and expression of full-length cDNA encoding human vitamin D receptor. Proc. Natl. Acad. Sci. 85: 3294-3298.

Boehm, M.F., L. Zhang, B.A. Badea, S.K. White, D.E. Mais, E. Berger, C.M. Suto, M.E. Goldman, and R.A. Heyman. 1994. Synthesis and structure-activity relationships of novel retinoid X receptor-selective retinoids. I. Med. Chem. 37: 29302941.

Davis, K.D., T.J. Berrodin, J.E. Stelmach, J.D. Winkler, and M.A. Lazar. 1994. Endogenous retinoid X receptors can function as hormone receptors in pituitary cells. Mol. Cell. Biol. 14: 7105-7110.

Devereux, J., P. Haeberli, and O. Smithies. 1984. A comprehensive set of sequence analysis programs for the VAX. Nucleic Acids Res. 12: 387-395.

Fields, S. and O. Song. 1989. A novel genetic system to detect protein-protein interactions. Nature 340: 245-246.

Giguére, V. 1994. Retinoic acid receptors and cellular retinoid binding proteins: Complex interplay in retinoid signaling. Endocrinol. Rev. 15: 61-79.

Giguére, V., S.M. Hollenberg, M.G. Rosenfeld, and R.M. Evans. 1986. Functional domains of the human glucocorticoid receptor. Cell 46: 645-652.

Giguére, V., E.S. Ong, P. Segui, and R.M. Evans. 1987. Identification of a receptor for the morphogen retinoic acid. Nature 330: 624-629.

Glass, C.K. 1994. Differential recognition of target genes by 
nuclear receptor monomers, dimers, and heterodimers. Endocrinol. Rev. 15: 391-407.

Harmon, M.A., M.F. Boehm, R.A. Heyman, and D.J. Mangelsdorf. 1995. Activation of a mammalian retinoid X receptor by the insect growth regulator, methoprene. Proc. Natl. Acad. Sci. (in press).

Heery, D.M., T. Zacharewski, B. Pierrat, H. Gronemeyer, P. Chambon, and R. Losson. 1993. Efficient transactivation by retinoic acid receptors in yeast requires retinoid $\mathrm{X}$ receptors. Proc. Natl. Acad. Sci. 90: 4281-4285.

Heyman, R.A., D.J. Mangelsdorf, J.A. Dyck, R.B. Stein, G. Eichele, R.M. Evans, and C. Thaller. 1992.9-Cis retinoic acid is a high affinity ligand for the retinoid $\mathrm{X}$ receptor. Cell 68: $397-406$.

Hollenberg, S.M. and R.M. Evans. 1988. Multiple and cooperative trans-activation domains of the human glucocorticoid receptor. Cell 55: 899-906.

Hollenberg, S.M., C. Weinberger, E.S. Ong, G. Cerelli, A.E. Oro, R. Lebo, E.B. Thompson, M.G. Rosenfeld, and R.M. Evans. 1985. Primary structure and expression of a functional human glucocorticoid receptor cDNA. Nature 318: 635-641.

Kang, T., T. Martins, and I. Sadowski. 1993. Wild type GAL4 binds cooperatively to the GAL1-10 UAS $\mathrm{U}_{\mathrm{G}}$ in vitro. $/$. Biol. Chem. 268: 9629-9635.

Kastner, P., J.M. Grondona, M. Mark, A. Gansmuller, M. LeMeur, D. Decimo, J.-L. Vonesch, P. Dollé, and P. Chambon. 1994a. Genetic analysis of RXR $\alpha$ developmental function: Convergence of RXR and RAR signaling pathways in heart and eye morphogenesis. Cell 78: 987-1003.

Kastner, P., M. Leid, and P. Chambon. 1994b. The role of nuclear retinoic acid receptors in the regulation of gene expression. In Viamin $A$ in health and disease (ed. R. Blomhoff), pp. 189-238. Marcel Dekker, New York.

Kliewer, S.A., K. Umesono, D.J. Mangelsdorf, and R.M. Evans. 1992a. Retinoid X receptor interacts with nuclear receptors in retinoic acid, thyroid hormone and vitamin $\mathrm{D}_{3}$ signalling. Nature 355: 446-449.

Kliewer, S.A., K. Umesono, D.J. Noonan, R.A. Heyman, and R.M. Evans. 1992b. Convergence of 9-cis retinoic acid and peroxisome proliferator signalling pathways through heterodimer formation of their receptors. Nature 358: 771-774.

Koelle, M.R., W.S. Talbot, W.A. Segraves, M.T. Bender, P. Cherbas, and D.S. Hogness. 1991. The Drosophila EcR gene encodes an ecdysone receptor, a new member of the steroid receptor superfamily. Cell 67: 59-77.

Kurokawa, R., V.C. Yu, A. Näär, S. Kyakumoto, Z. Han, S. Silverman, M.G. Rosenfeld, and C.K. Glass. 1993. Differential orientations of the DNA-binding domain and carboxy-terminal dimerization interface regulate binding site selection by nuclear receptor heterodimers. Genes \& Dev. 7: 1423-1435.

Kurokawa, R., J. DiRenzo, M. Boehm, J. Sugarman, B. Gloss, M.G. Rosenfeld, R.A. Heyman, and C.K. Glass. 1994. Regulation of retinoid signalling by receptor polarity and allosteric control of ligand binding. Nature 371: 528-531.

Leid, M., P. Kastner, and P. Chambon. 1992a. Multiplicity generates diversity in the retinoic acid signalling pathways. Trends Biochem. Sci. 17: 427-433.

Leid, M., P. Kastner, R. Lyons, H. Nakshatri, M. Saunders, T. Zacharewski, J.-Y. Chen, A. Staub, J.-M. Garnier, S. Mader, and P. Chambon. 1992b. Purification, cloning, and RXR identity of the HeLa cell factor with which RAR or TR heterodimerizes to bind target sequences efficiently. Cell 68: 377-395.

Levin, A.A., L.J. Sturzenbecker, S. Kazmer, T. Bosakowski, C. Huselton, G. Allenby, J. Speck, C. Kratzeisen, M. Rosenberger, A. Lovey, and J.F. Grippo. 1992. 9-Cis retinoic acid stereoisomer binds and activates the nuclear receptor RXR $\alpha$. Nature 355: 359-361.

Mangelsdorf, D.J., E.S. Ong, J.A. Dyck, and R.M. Evans. 1990. Nuclear receptor that identifies a novel retinoic acid response pathway. Nature 345: 224-229.

Mangelsdorf, D.J., K. Umesono, S.A. Kliewer, U. Borgmeyer, E.S. Ong, and R.M. Evans. 1991. A direct repeat in the cellular retinol-binding protein type II gene confers differential regulation by RXR and RAR. Cell 66: 555-561.

Mangelsdorf, D.J., U. Borgmeyer, R.A. Heyman, J.Y. Zhou, E.S. Ong, A.E. Oro, A. Kakizuka, and R.M. Evans. 1992. Characterization of three RXR genes that mediate the action of 9-cis retinoic acid. Genes \& Dev. 6: 329-344.

Mangelsdorf, D.J., K. Umesono, and R.M. Evans. 1994. The retinoid receptors. In The retinoids, 2nd ed. (ed. M.B. Sporn, A.B. Roberts, and D.S. Goodman), pp. 319-349. Raven Press, New York.

Marks, M.S., P.L. Hallenbeck, T. Nagata, J.H. Segars, E. Appella, V.M. Nikodem, and K. Ozato. 1992. H-2RIIBP (RXR $\beta$ ) heterodimerization provides a mechanism for combinatorial diversity in the regulation of retinoic acid and thyroid hormone responsive genes. EMBO J. 11: 1419-1435.

Nagpal, S., M. Saunders, P. Kastner, B. Durand, H. Nakshatri, and P. Chambon. 1992. Promoter context- and response element-dependent specificity of the transcriptional activation and modulating functions of retinoic acid receptors. Cell 70: 1007-1019.

Nagpal, S., S. Friant, H. Nakshatri, and P. Chambon. 1993. RARs and RXRs: Evidence for two autonomous transactivation functions (AF-1 and AF-2) and heterodimerization in vivo. EMBO I. 12: 2349-2360.

Perlmann, T., P.N. Rangarajan, K. Umesono, and R.M. Evans. 1993. Determinants for selective RAR and TR recognition of direct repeat HREs. Genes \& Dev. 7: 1411-1422.

Sadowski, I. and M. Ptashnc. 1989. A vector for expressing GAL4(1-147) fusions in mammalian cells. Nucleic Acids Res. 17: 7539.

Sande, S. and M.L. Privalsky. 1994. Reconstitution of thyroid hormone receptor and retinoic acid receptor function in the fission yeast Schizosaccharomyces pombe. Mol. Endocrinol. 8: $1455-1464$.

Shinar, D.M., N. Endo, S.J. Rutledge, R. Vogel, G.A. Rodan, and A. Schmidt. 1994. NER, a new member of the gene family encoding the human steroid hormone nuclear receptor. Gene 147: 273-276.

Song, C., J.M. Kokontis, R.A. Hiipakka, and S. Liao. 1994. Ubiquitous receptor: A receptor that modulates gene activation by retinoic acid and thyroid hormone receptors. Proc. Natl. Acad. Sci. 91: 10809-10813.

Sucov, H.M., K.K. Murakami, and R.M. Evans. 1990. Characterization of an autoregulated response element in the mouse retinoic acid receptor type $\beta$ gene. Proc. Natl. Acad. Sci. 87: 5392-5396.

Sucov, H.M., E. Dyson, C.L. Gumeringer, J. Price, K.R. Chien, and R.M. Evans. 1994. RXR $\alpha$ mutant mice establish a genetic basis for vitamin A signaling in heart morphogenesis. Genes \& Dev. 8: 1007-1018.

Titcomb, M.W., M.M. Gottardis, I.W. Pike, and E.A. Allegretto. 1994. Sensitive and specific detection of retinoid receptor subtype proteins in cultured cell and tumor extracts. Mol. Endocrinol. 8: 870-877.

Triezenberg, S.J., R.C. Kingsbury, and S.L. McKnight. 1988. Functional dissection of VP16, the trans-activator of herpes simplex virus immediate-early gene expression. Genes \& Dev. 2: 718-729.

Umesono, K., K.K. Murakami, C.C. Thompson, and R.M. 
Evans. 1991. Direct repeats as selective response elements for the thyroid hormone, retinoic acid, and vitamin $D_{3}$ receptors. Cell 65: 1255-1266.

Weinberger, C., C.C. Thompson, E.S. Ong, R. Lebo, D.J. Gruol, and R.M. Evans. 1986. The c-erb-A gene encodes a thyroid hormone receptor. Nature 324: 641-646.

Yao, T.-P., B.M. Forman, Z. Jiang, L. Cherbas, J.-D. Chen, M. McKeown, P. Cherbas, and R.M. Evans. 1993. Functional ecdysone receptor is the product of $E c R$ and Ultraspiracle genes. Nature 366: 476-479.

Yu, V.C., C. Delsert, B. Andersen, I.M. Holloway, O.V. Devary, A.M. Näär, S.Y. Kim, J.-M. Boutin, C.K. Glass, and M.G. Rosenfeld. 1991. RXR $\beta$ : A coregulator that enhances binding of retinoic acid, thyroid hormone, and vitamin $\mathrm{D}$ receptors to their cognate response elements. Cell 67: 1251-1266.

Zhang, X., B. Hoffmann, P.B.-V. Tran, G. Graupner, and M. Pfahl. 1992a. Retinoid X receptor is an auxiliary protein for thyroid hormone and retinoic acid receptors. Nature 355: $441-446$.

Zhang, X., J. Lehmann, B. Hoffmann, M.1. Dawson, J. Cameron, G. Graupner, T. Hermann, P. Tran, and M. Pfahl. 1992b. Homodimer formation of retinoid $\mathrm{X}$ receptor induced by 9-cis retinoic acid. Nature 358: 587-591. 


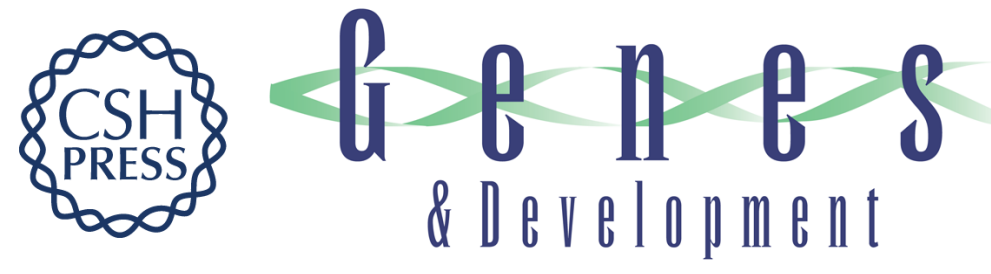

\section{LXR, a nuclear receptor that defines a distinct retinoid response pathway.}

P J Willy, K Umesono, E S Ong, et al.

Genes Dev. 1995, 9:

Access the most recent version at doi:10.1101/gad.9.9.1033

References This article cites 46 articles, 13 of which can be accessed free at: http://genesdev.cshlp.org/content/9/9/1033.full.html\#ref-list-1

License

Email Alerting

Service

Receive free email alerts when new articles cite this article - sign up in the box at the top right corner of the article or click here.

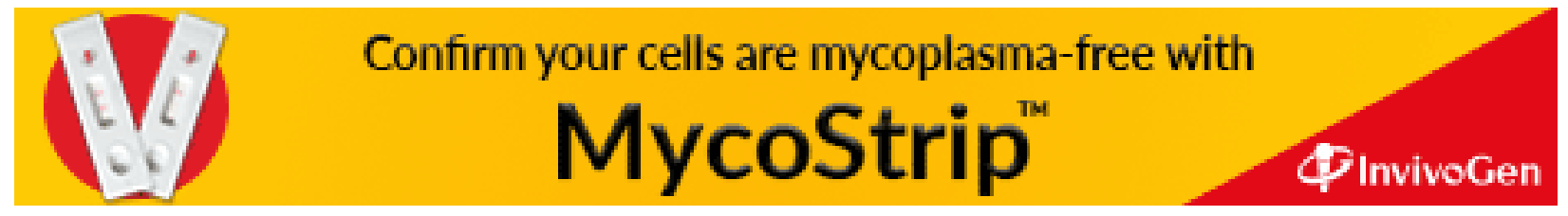

